\title{
A randomized controlled trial to evaluate the effect of addition of a single dose of epidural magnesium sulphate on the duration of postoperative analgesia in patients undergoing lower abdominal surgeries under epidural anaesthesia
}

\author{
*A Gupta ${ }^{1}$, VK Goyal ${ }^{2}$, N Gupta ${ }^{3}$, Rane $^{4}$, MNC Patil $^{5}$ \\ Specialist Anaesthesiology, ${ }^{I}$ ESI Hospital, Okhala, New Delhi, Senior Resident ${ }^{2}$, MAMC and \\ associated Hospital, New Delhi, Assistant Professor ${ }^{3}$, AIIMS, New Delhi, Professor ${ }^{4}$, Associate \\ Professor ${ }^{5}$, JN medical College, KLE's University, Belgaum, Karnataka. India.
}

*Corresponding author: dranjugupta2009@rediffmail.com

\begin{abstract}
:
Background: Noxious stimuli release excitatory neurotransmitters such as glutamate and aspartate, which bind to various receptors including N-methyl-D-aspartate (NMDA) receptors. Magnesium is a NMDA antagonist and has antinociceptive effects in animal and human models of pain. The addition of magnesium to postoperative epidural infusion may decrease postoperative pain and requirement of opioids.

Methods: Sixty patients undergoing elective total abdominal hysterectomies were enrolled to receive either $1 \mathrm{ml}$ of magnesium sulfate $(50 \mathrm{mg} / \mathrm{ml}$ ) (Group M) or $1 \mathrm{ml}$ of saline (Group C) in the epidural anaesthetic solution ( $9 \mathrm{ml}$ of $0.125 \%$ bupivacaine) for postoperative analgesia. Fentanyl $1 \mu \mathrm{g} / \mathrm{kg}$ was given epidurally as rescue analgesia. Haemodynamic parameters, pain assessment using a visual analogue scale (VAS), and fentanyl consumption were recorded in the postoperative period.

Results: There was significant difference between groups in the time to first analgesic requirement. Compared with Group C, patients in Group M received smaller doses of epidural fentanyl $(\mathrm{P}<0.001)$. The cumulative fentanyl consumption in $24 \mathrm{~h}$ was significantly lower in Group M $(119 \pm 56 \mathrm{mg})$ as compared to Group C $(267.8 \pm 92 \mathrm{mg})(\mathrm{P}$ $<0.001)$. Patients in Group M had less pain as measured via VAS score in the first hour of the postoperative period $(\mathrm{P}<0.001)$. The groups were similar with respect to haemodynamic and respiratory variables, sedation, pruritus, and nausea.

Conclusion: Administration of magnesium to epidural local anaesthetic solution provides longer duration of postoperative analgesia and reduced postoperative fentanyl consumption without added side-effects.
\end{abstract}

Keywords: analgesic techniques, epidural; pain, postoperative; pharmacology, fentanyl.

\section{Introduction:}

There has been substantial progress in our understanding of pain mechanisms, pharmacology and physiology of nociceptive processes and identification of neurotransmitters and pathways. Effective treatment of post-operative pain blunts autonomic, somatic and endocrine responses which ultimately enhance the recovery. Despite availability of many new additives for central neuraxial blockade, there is a constant search for better additives to increase duration of analgesia with minimum side effects. ${ }^{1}$
Magnesium is the fourth most plentiful cation in the body and a NMDA antagonist.

Activation of NMDA receptors leads to calcium entry into the cell and initiates a series of secondary events which are responsible for pain. So, signaling of these receptors is important in determining the duration of analgesia. Intravenous (i.v.) or intrathecal magnesium administration, has been shown to improve anaesthetic and analgesic quality. 2, 3, 4 Epidural anaesthesia is a safe and inexpensive technique for abdominal and lower limb 
surgeries of long duration, with the added advantage of extending the pain relief in the postoperative period. There is limited literature on the effect of magnesium administered epidurally and there is no report on an Indian population to date.

We therefore conducted a prospective, randomized, double blind controlled clinical trial with a hypothesis that the addition of $1 \mathrm{ml}$ magnesium sulfate $(50 \mathrm{mg} / \mathrm{ml})$ to epidural anaesthestic solution in the postoperative period may decrease the requirements for fentanyl and may improve the quality of analgesia.

\section{Methods:}

After Institutional review board approval and written informed consent, this randomized placebo controlled double blind trial was done in 60 ASA grade I/ II adult patients (20 to 55 years) undergoing elective total abdominal hysterectomies of duration less than 120 minutes under epidural anaesthesia.

Patients with history of convulsions and multiple allergies, with major systemic illnesses, pregnant and lactating women and those having contraindications for epidural block were excluded from the study.

All patients were premedicated with oral alprazolam $0.25 \mathrm{mg}$ and ranitidine $150 \mathrm{mg} 2 \mathrm{~h}$ before surgery. Visual analogue pain scale (VAS: 0: no pain, 10: worst pain ever) was explained to the patients before the operation. Standard monitors were applied in all the patients. After i.v. access had been established and an infusion of crystalloid commenced, all patients received epidural anaesthesia. The epidural space was identified at L3-4 or L4-5 using a loss-of-resistance to air technique and an epidural catheter was then advanced for 3-4 $\mathrm{cm}$ into the epidural space.

Epidural anaesthesia was instituted with $0.5 \%$ bupivacaine through the catheter, to achieve a block above T8 level. Sensory block was assessed bilaterally by using analgesia to pinprick. When surgery was complete, the patients were randomly allocated into two groups using computer generated randomization to receive $1 \mathrm{ml}$ of $50 \mathrm{mg} / \mathrm{ml}$ magnesium sulphate ( group $\mathrm{M}$ ) or $1 \mathrm{ml}$ of normal saline ( group C) in $10 \mathrm{ml}$ epidural anaesthetic solution (9 $\mathrm{ml} \quad 0.125 \%$ bupivacaine) given slowly over $10-15$ minutes with haemodynamic monitoring. The analgesic regimen was prepared by the anaesthesiologist managing the patient, who was not subsequently involved in data collection. It was commenced in the recovery room while the block was still effective. Patients and nursing staff were also blinded to the group randomization.

Hypotension was defined as $20 \%$ decrease from baseline, and was treated with an i.v. fluid bolus of $500 \mathrm{ml}$ of lactated Ringer's solution followed by i.v. ephedrine $5 \mathrm{mg}$ if required.

In the postoperative period respiratory rate (RR), heart rate( HR), systolic blood pressure (SBP), diastolic blood pressure (DBP) and mean blood pressure (MBP) were monitored at $30 \mathrm{~min}$, and then at $0,1,2,4,8,12$, and 24 h. Postoperatively pain was assessed using VAS scoring at $0,1,2,4,8,12$, and 24 hours. A resting VAS score $<3$ was considered satisfactory. If patients had inadequate analgesia (VAS > 3), epidural fentanyl $1 \mathrm{mcg} / \mathrm{kg}$ in $10 \mathrm{ml}$ normal saline was administered as supplementary rescue analgesic. The duration of analgesia and total consumption of opioid was evaluated. Adverse events related with the drugs (drowsiness, respiratory depression, nausea, vomiting, pruritus) and epidural catheter were recorded throughout the $24 \mathrm{hr}$ study period. All patients enrolled in the study were thoroughly evaluated for any neurological or systemic toxicity at the time of discharge and were instructed to report back in case of any complication.

Statistical analysis: All data are expressed as mean \pm standard deviation (SD). Statistical analysis was done using $t$ test and a ' $p$ ' value of less than 0.05 was considered to be significant. On the basis of published data, we determined that a sample size of 25 patients per group would have $80 \%$ power to detect a decrease in consumption of fentanyl by 
$100 \mathrm{mcg}$ with SD of $115 \mathrm{mcg}$ and $\alpha=0.05$ difference. So, we decided to take 30 patients in each group.

\section{Results:}

There were no differences in the demographic characteristics of the patients and duration of surgery in the two groups (Table 1 and 2). The mean VAS scores were higher in the control group at all times of comparison. The difference between the two groups was maximum at 4 hours postoperatively. $(\mathrm{P}<0.05)$ (Figure 1) No differences were found in cardio respiratory variables (MAP, SBP, DBP, HR, $\mathrm{RR}$ or $\mathrm{SpO} 2$ ). They were comparable at all times of measurement. The changes of MAP are shown in Figure 2.

Patients in group $M(351 \pm 64.07$ minutes) had significantly longer duration of analgesia than group C (186 \pm 75.32 minutes) (Table 2$)(\mathrm{P}<$ $0.001)$. Patients in the Group $C$ required more post-operative fentanyl doses than patients receiving magnesium $(2.2 \pm 1.04$ in group $\mathrm{M}$ vs. $4.9 \pm 1.51$ in group $\mathrm{C})$. (Table 2$)(\mathrm{P}<$ 0.001). Total fentanyl consumption was also higher in the control group. $\quad(119.2 \pm 56.24 \mu \mathrm{g}$ in group $\mathrm{M}$ vs. $267.2 \pm 92.14 \mu \mathrm{g}$ in group $\mathrm{C}$ ) (Table 2) $(\mathrm{P}<0.001)$ No intra-operative complications of importance developed during the study period and at hospital discharge.

Table 1: Demographic data

\begin{tabular}{|l|c|c|}
\hline $\begin{array}{l}\text { Demographic } \\
\text { variable }\end{array}$ & Group M & Group C \\
\hline Age ( years) & $44.6 \pm 8.54$ & $41.7 \pm 7.82$ \\
Height $(\mathrm{cm})$ & $158.3 \pm 8.34$ & $156.7 \pm 7.82$ \\
Weight $(\mathrm{kg})$ & $\mathbf{5 4 . 9} \pm 6.25$ & $\mathbf{5 4 . 2} \pm 8.06$ \\
\hline
\end{tabular}

Table 2: Clinical parameters in the two groups.

\begin{tabular}{|llll|}
\hline Parameter & Group M & Group C & 'P' VALUE \\
\hline $\begin{array}{l}\text { Duration of } \\
\text { surgery } \\
\text { (minutes) }\end{array}$ & $99.6 \pm 10.50$ & $93.6 \pm 13.1$ & 0.056 \\
$\begin{array}{l}\text { Duration of } \\
\text { analgesia } \\
\text { (minutes) }\end{array}$ & $351 \pm 64.07$ & $186 \pm 75.32$ & $<0.001$ \\
$\begin{array}{l}\text { No. of fentanyl } \\
\text { doses } \\
\text { (number) }\end{array}$ & $2.2 \pm 1.04$ & $4.9 \pm 1.51$ & $<0.001$ \\
$\begin{array}{l}\text { Total fentanyl } \\
\text { consumption( } \mu\end{array}$ & $119.2 \pm 56.24$ & $267.2 \pm 92$. & $<0.001$ \\
g) & & 14 & \\
\hline
\end{tabular}

Figure 1: Pain scores

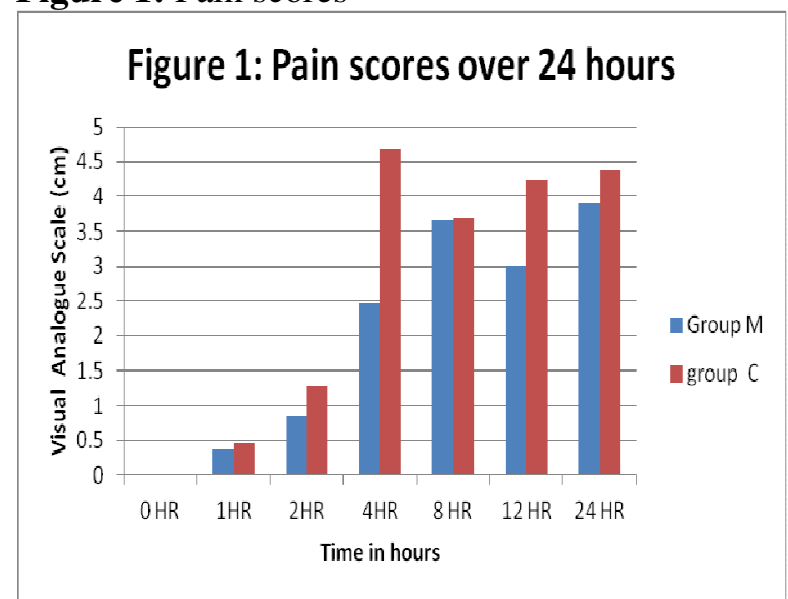

Figure 2 : MAP over $24 \mathrm{hrs}$

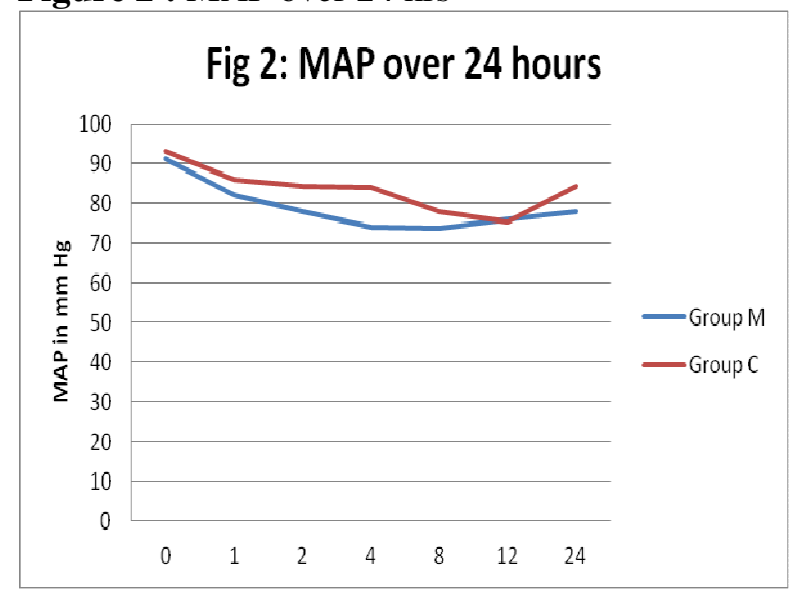

\section{Discussion}

The aim of postoperative analgesic management is to provide adequate analgesia without major side-effects. Traditionally opioids have been used epidurally with local anaesthetics to prolong the duration of epidural analgesia. But larger doses of opioids may be associated with side-effects like respiratory depression, urinary retention and pruritus. ${ }^{6}$ The administration of opioids with opioid sparing drugs thus may reduce the above mentioned side effects and be beneficial in the postoperative period.

It is well known that the painful stimuli release neurotransmitters, which may activate NMDA receptors. Activation of these receptors modulates calcium entry into the cell, and has an important role in pain perception. Therefore, NMDA receptor 
antagonists play a role in the treatment of postoperative pain. ${ }^{1,2,3}$

Recently, magnesium has been used as an adjuvant to drugs for perioperative analgesia. It blocks calcium influx and non-competitively antagonizes NMDA receptor channels. It has also been shown to have analgesic effect similar to opioids. When given with opioids, it significantly reduces the opioid requirement for postoperative pain relief. ${ }^{2}$

Most of the studies reported in the literature have used a bolus dose of epidural magnesium followed by an infusion as well. Bilir et al in their study had used magnesium sulphate 50 $\mathrm{mg}$ in $5 \mathrm{ml}$ volume as a bolus dose followed by a continuous epidural infusion of $100 \mathrm{mg}$ at a total $24 \mathrm{ml}$ volume for $24 \mathrm{hrs}$ for patients undergoing orthopaedic surgeries. Other authors have used even higher doses. ${ }^{3,7}$ Based on above mentioned literature and the dose response curve in animal studies, ${ }^{8}$ we planned our study to evaluate the effect of a single dose of magnesium sulphate $(1 \mathrm{ml}$ of $50 \mathrm{mg} / \mathrm{ml}$ $\mathrm{MgSO}_{4}$ in $9 \mathrm{ml} 0.125 \%$ bupivacaine) on quality of postoperative analgesia and postoperative fentanyl consumption.

In our study, post-operative analgesia was assessed by VAS scoring which was significantly better in group $\mathrm{M}$ as compared to the group $\mathrm{C}$. The difference in mean VAS score in the two groups peaked at 4 hours, warranting earlier requirement of rescue analgesic. (Fig 2) $(\mathrm{P}<0.05)$ Moreover, the patients in group $\mathrm{M}$ required lesser number of doses and total dose of fentanyl in the postoperative period $(119 \mu \mathrm{g}$ in Group M vs $267 \mu \mathrm{g}$ in Group C) than group $\mathrm{C}(\mathrm{P}<0.001)$ (Table 2). Our study has shown that there is significant reduction in consumption of fentanyl with epidural magnesium, similar to that reported previously in the literature. ${ }^{6,9}$ Arcioni et al also concluded that preemptive administration of intrathecal and epidural magnesium as an additive significantly decreased the postoperative opioid requirement. ${ }^{3}$ Thus our study reaffirms that magnesium when co administered with opioids, has an opioid sparing action.

The epidural dose of magnesium in our study was too low to have systemic effects. This analgesic effect may have been due to the penetration of magnesium through the spinal meninges or may be related to the diffusion of magnesium from the dura. Local anaesthetics (LA) act not only by binding to receptors on the sodium $(\mathrm{Na}+)$ channel but also by displacing calcium $(\mathrm{Ca} 2+)$ from $\mathrm{Na}+$ channel receptor site. Magnesium causes hyperpolarisation and exaggerates this inhibition. LA-mediated modulation of NMDA receptors could also contribute to regional anaesthesia. ${ }^{10}$ Magnesium blocks $\mathrm{Ca} 2+$ influx and also acts as non-competitive NMDA receptor antagonist. So this synergistic relationship between LA and magnesium abolishes peripheral afferent noxious stimulation and prevents the central sensitization of nociceptors. ${ }^{10}$

In our study the haemodynamics were stable postoperatively in both groups. The MAP was similar in both groups at all times of comparison. The graph suggests a higher MAP at 4 and 8 hour postoperatively in group $\mathrm{C}$, coinciding with the time to rescue analgesic, but this was not statistically significant. (Fig 1 and 2). None of the patients in either group had arterial hypotension or cardiac arrhythmias warranting treatment. Also there were no signs of systemic toxicity such as somnolence, double vision, slurred speech or weakness in any of our patients. In animals, magnesium administered through central neuraxial route (spinal or epidural) has been shown to have a good safety profile similar to that of LA. ${ }^{11,12}$ Recent literature also confirms the safety of magnesium administered through epidural or interathecal route. $3,6,7,13,14$ Goodman and colleagues noted that larger doses $(8.7 \mathrm{gm}, 9.6 \mathrm{gm})$ of magnesium inadvertently administered into epidural space do not cause any neurological injury. ${ }^{15}$

Our clinical trial also reiterates that the safety profile of epidurally administered $\mathrm{MgSO} 4$ is remarkably good.

Conclusion: Supplementation of epidural local anaesthetic with $50 \mathrm{mg}$ magnesium sulfate considerably prolongs the postoperative analgesia and reduces fentanyl consumption in patients posted for lower abdominal surgeries. The results of the present investigation suggest use of epidural 
magnesium as a low cost adjuvant for epidural analgesia.

Lacunae: Our study has the limitation of only one dose-response evaluation. We preferred to use a smaller dose of magnesium that would not cause any side-effects. Studies emphasizing different doses of magnesium can be undertaken.

\section{References}

1. Laurent Dubé, Jean-Claude Granry. The therapeutic use of magnesium in anesthesiology, intensive care and emergency medicine: a review. CJA 2003; 50: 732-46

2.Farouk S. Pre-incisional epidural magnesium provides pre-emptive and preventive analgesia in patients undergoing abdominal hysterectomy. British Journal of Anaesthesia 2008; 101 (5): 694-9. http://dx.doi.org/10.1093/bja/aen274

PMid:18820247

3. Arcioni R, Palmisani S, Tigano S et al. Combined intrathecal and epidural magnesium sulphate supplementation of spinal anesthesia to reduce post-operative analgesic requirements: a prospective, randomized, double-blind, controlled trial in patients undergoing major orthopaedic surgery. Acta Anaesthesiol Scand 2007; 51: 482-89 http://dx.doi.org/10.1111/j.1399-6576.2007.01263.x PMid:17378788

4.Buvanendran A, Mc Carthy RJ, Kroin JS, Leong W et al. Intrathecal magnesium prolongs fentanyl analgesia: a prospective, randomized, controlled trial. Anesth Analg 2002; 95:661-7

PMid:12198056

5.Chaney MA. Side effects of intrathecal and epidural opioids. Can J Anaesth. 1995 Oct;42(10): 891-903.

http://dx.doi.org/10.1007/BF03011037

PMid:8706199

6. Bilir A, Gulec S, Erkan A, Ozcelik A. Epidural magnesium reduces postoperative analgesic requirement. Br J Anaesth 2007; 98:519-23

http://dx.doi.org/10.1093/bja/aem029

PMid:17324976

7. Yousef AA, Amr YM. The effect of adding magnesium sulphate to epidural bupivacaine and fentanyl in elective caesarean section using combined spinalepidural anaesthesia: a prospective double blind randomised study. Int J Obstet Anesth.

2010 Oct;19(4):401-4.

http://dx.doi.org/10.1016/j.ijoa.2010.07.019

PMid:20833531
8. Saeki H, Matsumoto M, Kaneko S, Tsuruta S, Cui YJ, Ohtake K, et al. Is intrathecal magnesium sulfate safe and protective against ischemic spinal cord injury in rabbits? Anesth Analg 2004;99:1805-12. http://dx.doi.org/10.1213/01.ANE.0000138039.04548.3D PMid:15562076

9. Asokumar B, Newman LM, McCarthy RJ, Ivankovich AD, Tuman KJ. Intrathecal magnesium prolongs fentanyl analgesia: a prospective, randomized controlled trial. Anesth Analg 1998; 87: 1309-15. http://dx.doi.org/10.1213/00000539-199812000-00018 PMid:9842818

10. Sirvinskas E, Laurinaitis R. Use of magnesium sulfate in Anesthesiology. Medicine 2002; 38: 147-50

11. Follis F, Miller K, Scremin OU, Pett S, Kessler R, Wernly J. NMDA receptor blockade and spinal cord ischemia due to aortic cross clamping in the rat model. Can J Neurol Sci 1994;21: 227-32.

PMid:8000978

12. Simpson JI, Eide TR, Schiff GA et al. Intrathecal magnesium sulfate protects the spinal cord from ischemic injury during thoracic aortic cross-clamping. Anesthesiology 1994; 81:1493-9.

http://dx.doi.org/10.1097/00000542-199412000-00025 PMid:7992919

13. Dror A, Henriksen E. Accidental epidural magnesium sulphate injection. Anesth Analg 1987; 66: 1020-1. http://dx.doi.org/10.1213/00000539-198710000-00020 PMid:3631562

14. Ozalevli M, Cetin TO, Unlugenc H, Guler T, Isik G. The effect of adding intrathecal magnesium sulphate to bupivacaine- fentanyl spinal anaesthesia. Acta Anaesthesiol Scand 2005; 49: 1514-9.

http://dx.doi.org/10.1111/j.1399-6576.2005.00793.x PMid:16223399

15. Goodman EJ, Haas AJ, Kantor GS. Inadvertent administration of magnesium sulphate through epidural catheter: report and analysis of a drug error. Int J Obs Anesth 2006; 15: 63-7

http://dx.doi.org/10.1016/j.ijoa.2005.06.009

PMid:16256336 